Ocke-Schwen Bohn, Murray J. Munro (eds)

\section{Language Experience in Second Language Speech Learning: In Honor of James Emil Flege}

Language Learning and Language Teaching 17 Benjamins, Amsterdam 2007

406 pp.; EUR 115.00, USD 173.00

ISBN 978-90-272-1973-2

Published to mark James Flege's retirement, this collection of papers is a fitting tribute to one of the most influential and probably the most prolific scientists in the field of second language (L2) speech research. In 365 pages 20 papers offer discussion and present empirical findings on a wide variety of topics from the field of second- or foreign-language research, and a further 40 pages of bibliography, name and subject indexes complete a fascinating picture of present-day L2 research. Inevitably, since the book is a festschrift for an American scholar, there is a preponderance of North American or North-America-based authors among the 30 contributors (22, with 3 each based in Scandinavia and Australia, respectively, 1 in Japan and 1 in Germany). Flege's Speech Learning Model (SLM) is at the centre - or at least is the shared focus - of a large majority of the articles. This no doubt reflects both the authors' respect for his work and the extent of his influence in the field.

As the editors write, all the central themes of pronunciation research receive attention from one or more papers. However, it is not our intention to duplicate the useful theme-orientated commentary offered by the editors in their introductory overview. We therefore try to capture the main thrust, with comments on the merits and points of special interest, of the individual papers in the order they are presented in five thematic sections, which form the structuring framework for the 20 papers. These sections are: Part I - The Nature of L2 Speech Learning, Part II - The Concept of Foreign Accent, Part III - Consonants and Vowels, Part IV - Beyond Consonants and Vowels, and Part V - Emerging Issues. It must be said, however, that the subsection titles do not necessarily capture a particular thread running through the component papers. The book is not an a priori structured work, but rather a chance collection by established scientists and colleagues of James Flege. The titles of Parts I-V must therefore be taken as only rough guides to the orientation of the papers they contain.

Part I is opened by the editors' introduction, 'The Study of Second Language Speech: A Brief Overview', which serves both as a laudation and as a theoretical orientation to the 19 other contributions. It adds a historical perspective to the picture of L2 research that emerges in the course of the volume and provides some hints at possible future work for those looking to continue the effort. The four other papers in Part I consider foreign-language perception from different angles.

Catherine Best and Michael Tyler ('NonNative and Second-Language Speech Perception') provide a theoretically concentrated discussion of the similarities and differences between Flege's SLM and their own Perceptual Assimilation Model (PAM). Stressing the basically different orientation - SLM being concerned with L2 learning while PAM is a model to explain nonnative perception of a foreign language - they discuss the possible extension of PAM concepts to cover L2 phenomena. For those already familiar to some extent with the two models (though for the uninitiated the account is probably set at too high a level of abstraction), there is an illuminating contrapuntal explication of SLM postulates and PAM principles. Many of the differences in viewpoint, and possibly in the understanding of terms such as 'phonetic' and 'phonological', stem from a basic difference in as yet non-disprovable tenets, whether perception operates on concrete distal events (articulatory gestures) or mental representations (categories).

The chapter by Winifred Strange ('CrossLanguage Phonetic Similarity of Vowels') is much more concrete in its approach, providing a discussion of different approaches to cross-language phonetic comparison - articulatory, acoustic and perceptual - with examples of acoustic and perceptual analyses. The example data are both pertinent and convincing, and underline the two main messages, namely that analyses - whether of production or of perception - have to be

\footnotetext{
KARGER

(C) 2009 S. Karger AG, Basel 0031-8388/08/0654-0272

Fax +41 613061234 E-Mail karger@karger.ch www.karger.com

Accessible online at: www.karger.com/pho
} 
contextually sensitive, and that differences between L1 and L2 (in this case derived from discriminant analysis) are unreliable predictors of perceptual behaviour. Of particular interest, from a 'tutorial' point of view, is the methodological discussion that accompanies the experimental descriptions.

In their paper, 'Investigating the Role of Attention in Phonetic Learning', Susan Guion and Eric Pederson address a long-standing issue in teaching methodology, namely the way in which learners can actually be brought to discern differences between phonetic categories (assuming they exist) in L2 and L1. The results of two experiments show that English native speakers can develop abilities to distinguish very different perceptual categories such as Mandarin tones (study 1) and Hindi dental vs. retroflex stops (study 2). As might be expected, the conclusions differ for different learner groups. But for cognition-orientated theorists, the observation that adult learners can benefit from having their attention directed explicitly to the problem is encouraging.

The final paper in Part I, 'You Are What You Eat Phonetically: The Effect of Linguistic Experience on the Perception of Foreign Vowels' by Elaina Frieda and Takeshu Nozawa, provides another illustration of the cross-language assimilation-testing and goodness-rating paradigms discussed in Winifred Strange's paper, this time with Japanese (experienced and inexperienced), Korean and American (control) subjects. In addition, discriminability hypotheses derived from the results are tested in direct discrimination tests and partially confirmed (for beginners though not for experienced learners).

Under the title 'The Concept of Foreign Accent', Part II is a collection of three disparately orientated papers variously and loosely linked to the concept of foreign accent.

In his study on 'Nativelike Pronunciation among Late Learners of French as a Second Language' David Birdsong looks at the phonetic proficiency of adult learners of French as a second language. Nativelike pronunciation is observed among some subjects in terms of vowel duration and VOT in word lists and in terms of foreign- $/$ native accent rating by native speakers of French for read passages. The asymmetry and non-generalizability of quantitative results is apparent here as almost everywhere. Performance at sentence and text level can be used to predict performance at the segmental level, but not vice versa.

The second 'foreign-accent' paper is a contribution by Robert Allen Fox and Julie Tevis
McGory on 'Second Language Acquisition of a Regional Dialect of American English by Native Japanese Speakers'. They examine whether regional dialectal differences found in the vowel systems of American English in a Southern variety (Alabama) and a Standard variety (Ohio) are reflected in the production and perception behaviour of adult Japanese speakers living in the respective areas. Both groups of native Japanese speakers produced vowels that were more like those of the Ohio English speakers, though there was also a strong influence of the Japanese L1. In the Alabama learners there were few of the regional dialectal characteristics which distinguish the Southern variety from the more standard Ohio accent. The results of a vowel identification task indicated that exposure to the Southern dialect did not improve the perception of the Southern vowels. Both groups of Japanese speakers performed significantly worse when identifying Southerners' vowels.

In the last chapter dealing with the 'foreign accent' theme of Part II, Allard Jongman and Travis Wade ('Acoustic Variability and Perceptual Learning: The Case of Non-Native Accented Speech') take up and extend the scope of the issue whether phonetic categories are acquired better if learners are exposed to variable tokens of the category than if they are only presented with prototypical examples. The link to 'foreign accent' here is not to examine whether learners' accent is more nativelike but to explore the effect of training with demonstrably greater non-native variability on the learners' ability to recognize words. In other words, can learners deal with a foreign accent? Against the background of conflicting reports in the literature this paper offers more differentiated findings, indicating that the positive or negative effect of varied training material can change with the basic discriminability of the categories to be learned. There is also the - unsurprising - finding that Dutch learners more easily recognize (and consciously prefer) US-English L2 words that are pronounced with a Dutch accent.

Part III ('Consonants and Vowels') deals with four segmental pronunciation problems. Robert McAllister's study of Swedish learners' production of the sibilant voiced-voiceless opposition ('Strategies for Realization of L2-Categories: English /s/-/z/') takes a closer look at the 'feature' level of Flege's SLM, linked to SLM postulates 5 and 6 . These specify that the acquisition of a category can be blocked if a critical feature is not perceived but may, on the other hand, still be established successfully by means of other, non- 
distinctive but co-varying features. The two properties examined in the paper are the critical allophonic vowel-lengthening before /z/ in English (to which Swedish speakers might be expected to be sensitive in the light of their own quantity-critical language) and voicing during the fricative, which is considered to be redundant. The highly varying performance of the otherwise very competent Swedish speakers of English illustrates the inability of most of the subjects (15 from 17) to learn the allophonic vowel-length strategy for English /s/-/z/ differentiation. The use of voicing as a support feature is found in a greater number of subjects. Explanation for the lack of vowellength sensitivity is offered within perceptual compensation theory. One speaker achieved some degree of auditory acceptance without either feature, and it is unfortunate that the author offers no further acoustic analysis on this speaker. Some speculation about which property (e.g. relative intensity) might underlie this acceptance would have been welcome.

The study of Yue Wang and Dawn Behne ('Temporal Remnants from Mandarin in Nonnative English Speech') investigates temporal patterns of L1 and L2 in interaction within a syllable (actually making the study a prime candidate for allocation to Part IV rather than Part III). English stop-vowel syllables were produced by native American English speakers and native Chinese speakers, the latter also producing comparable Mandarin stop-vowel syllables. Results show that the internal timing of syllable components in nonnative English productions often deviates from native Chinese speech in the direction of Chineseaccented English, with the closure duration, VOT, and vowel duration being intermediate to nativeaccented speech and foreign-accented speech. These findings are discussed in the context of previous research on interlanguage behaviour and the gradual process of acquiring correct target-language pronunciation.

Anna Maria Schmidt examines native English speakers' perception of similarity in Korean syllable initial consonants ('CrossLanguage Consonant Identification: English and Korean'). Native English listeners' acoustic cue-weighting is clearly different from native Koreans, e.g. when they perceive tense and voiceless Korean stops and affricates as their voiced counterparts (irrespective of the following vowel). When nasals precede /i/ and /u/ (but not /a/) they are often classified as voiced stops, and the palatalized $/ \mathrm{s} / \mathrm{in} / \mathrm{si} /$ is perceived as $/ \mathrm{f} /$ (though not in other vowel contexts). The author argues for much more detailed consideration of the cross-language exploitation of acoustic cues in modeling L2 speech perception.

Ratree P. Wayland's study ('The Relationship between Identification and Discrimination in Cross-Language Perception: The Case of Korean and Thai') also has Korean as its object of interest, in this case paired with Thai rather than the almost inevitable English L2. Theoretically, the paper is closely related to Elaina Frieda's and Takeshu Nozawa's study of vowel categorization and evaluation (which could just as convincingly be part of Part III). Cross-language categorization and goodness judgments are examined with respect to their predictive value by comparing the discrimination predictions derived from isolated and contextualized (AXB) categorization with actual discrimination scores. As was the case with Frieda and Nozawa's paper, the results show the limitations of predicting discriminability direct from identification results. In this case the author highlights the problem of assuring comparable identification and discrimination tasks. From a phonetic point of view the quantitative description of Thai and Korean stops given by the author offers an interesting background to the contrasting perceptual behaviour of the two listener groups, though it receives little explicit discussion and speculation is left to the reader.

Part IV ('Beyond Consonant and Vowels') is concerned with non-segmental aspects of L2 learning. Three of the four articles in this section deal with the problem of acquiring (lexical) tone categories, an important general issue considering that (probably) the majority of the languages of the world are tone languages, and is of growing importance in the present socio-commercial climate. However, the relative size of this section and the limited scope of the phenomena covered in it are a reminder of what was not the focus of Jim Flege's research.

Terry L. Gottfried's paper ('Music and Language Learning: Effect of Musical Training on Learning L2 Speech Contrasts') takes another look at the much-studied relationship between musicality and language-learning ability within the context of perceiving and producing the four Mandarin tones. The careful control and discussion of factors that can explain some of the disparate results of past research puts the differences found here between musically trained (and/or musically active) and musically inexperienced subjects and the positive correlations between perception and production into a clearer perspective. 
The dutiful link made in the introduction between SLM theory and the issue under examination appears, however, just a little out of place.

In chapter 14, Joan A. Sereno and Yue Wang ('Behavioral and Cortical Effects of Learning a Second Language: The Acquisition of Tone') provide a valuable discussion of results from a number of different approaches to research into brain activity during L2 perception and production. Dichotic listening experiments showing lateralization effects and fMRI data converge to confirm once more the difference between the processing of linguistic and non-linguistic tonal contrasts. Importantly though, brain-scan data can show the effects of centralneural reorganization that comes with L2 training and also offers evidence for the complex interhemispheric interactions that are involved (in particular) in the processing of tonal properties of speech.

The paper by Denis Burnham and Karen Mattock ('The Perception of Tones and Phones') overlaps to some extent the territory covered by Sereno and Wang, but its consistent inclusion of the developmental dimension and the explicit focus on the tone-phone comparison makes it both informative in its own right and by virtue of its shift in perspective from the preceding paper. In a many-facetted discussion of tonal phenomena in their multi-level communicative functions, the authors focus on the development of both L1 and L2 (lexical) tonal categories and their different modes of representation and processing. They also provide interesting empirical data pertinent to such issues as the comparative status of tones and phones as linguistic elements and as auditory events, showing effects within and across language groups (primarily Thai and Australian English). Though they do not present any new results, the synthesis of information from their own and many other scientists' research makes for stimulating reading.

Katsura Aoyama and Susan G. Guion ('Prosody in Second Language Acquisition: Acoustic Analysis of Duration and $\mathrm{F}_{0}$ Range') investigate timing and melodic properties of native and Japanese-accented American English using an imitation task in a question-answer context. Both children and adults were recorded. As expected, non-native speakers show a lower articulation rate than native speakers, as do children in general compared to adults. Non-natives also have a proportionately longer duration of function words and a wider $\mathrm{F}_{0}$ range. The authors point out some limitations to their study, mentioning the restriction of the analysis to duration and $\mathrm{F}_{0}$ range. The restriction of the analysis to only 3 of the originally planned 10 utterances due to production difficulties experienced by the Japanese subjects should be added. Also no intonation analysis in terms of tonal accent contours is undertaken, and the lack of any perceptual evaluation of the Japanese productions is regrettable. Thus, intonation is effectively excluded from the scope of the festschrift, which is unfortunate in view of the strong position that prosody in general and intonation in particular have acquired in the past decade or so.

Four papers are allocated to Part V ('Emerging Issues'). The first is by Thorsten Piske, who examines the 'Implications of James E. Flege's Research for the Foreign Language Classroom'. This is less the recognition of an 'emerging' issue than the identification of a question which Flege's non-didactically orientated research simply did not (intend to) address. There are four factors that Piske identifies as important for students in a foreign language classroom to help them develop a high level of L2 proficiency. These are (a) an early starting age, (b) intensive use of the foreign language over a period of many years, (c) exposure to a substantial amount of high-quality input, and (d) training in the perception and production of L2 sounds. While it is important to make the relevance for the classroom explicit, these factors are, of course, no more than a direct transfer of the factors behind Flege's own postulates. The value of the paper, however, lies in the classroom-orientated discussion of Flege's and his colleagues' non-classroom research findings.

Amanda C. Walley's contribution ('Speech Learning, Lexical Reorganization, and the Development of Word Recognition by Native and NonNative English Speakers') discusses a theoretical issue linked with developmental aspects of word recognition which have implications for $\mathrm{L} 2$ and which bring in an aspect of speech perception which Flege's SLM cannot touch because of its speech-sound category orientation. The Lexical Restructuring Model - i.e., holistic rather than phonemic word recognition in younger listeners with changing lexical representation, from holistic to phonemic, as lexical competition increases with a growing vocabulary - suggests the possibility of a similar learning path in L2 learners. An earlier joint study with Flege is discussed which indeed illustrates how phonetic distinctiveness and lexical density interact to help or hinder lexical recognition. The effects are shown to be different in beginning and advanced learners. 
Tessa Bent, Ann R. Bradlow and Bruce L. Smith's paper 'Phonemic Errors in Different Word Positions and Their Effects on Intelligibility of Non-Native Speech: All's Well That Begins Well' aims to show the potential of differentiated phonetic analysis for revealing the effect of L1-L2 structural interactions on L2 intelligibility. They relate the varying segmental production accuracy of Chinese talkers of English to their overall intelligibility. The unsurprising finding that vowel accuracy and word-initial segments are more important to intelligibility (at least of English) than word-final segments is discussed in terms of 'universals' and language-specific properties.

The final contribution to the collection is Robert F. Port's paper ('The Graphical Basis of Phones and Phonemes'), which takes a probing look at the sound structure of language and our way of picturing and graphically representing it, provides a thought-provoking conclusion to the book. Though by no means the first linguist to have discussed the disadvantages as well as the advantages that the alphabetic notation of words and utterances have on our conception of language, and particularly sound structure, his thoughts and observations are a fitting reminder that, in L2 as in L1 research, we need to consider the communicative functions of an utterance in its entirety and not restrict our attention to traditional linguistic descriptive constructs.

As the short summaries and the comments have hopefully revealed, the contributions to this festschrift cover a wide range of issues in L2 research. However, in the nature of such collections, the factor influencing the choice of topics is the link to the scholar who is being honoured. This inevitably makes the potential reader group difficult to define. The dearth of new and original results means that the theoretical discussions will be of prime interest to experts in the field. The very useful surveys of past work in the many topics addressed are clearly of interest to nonexperts looking for a foothold from which to progress. However, since there is no didactic mission to accomplish the authors often assume that central theoretical concepts are known. This reduces the usefulness of the book for the "beginner'. But the volume provides many points of access for advanced seminar work and as a platform from which young researchers with an interest in the field can direct their work. Also, the 31 pages of references represent an extremely useful bibliographical resource for researchers.

Since Flege's SLM is part of, or starting point for the research in many of the contributions, it would have been useful if the editors had commented on links between the individual contributions in this respect, and on the relevance of the research for the model. In the event, the many mentions appear not to affect the model in any way.

A further consequence of the festschrift character is the basically non-representative nature of the contents. The North American bias has already been mentioned, and the relative neglect of L2 speech research in other parts of the world (the paper by Burnham and Mattock a notable exception) needs to be borne in mind. This is no criticism of the quality of research reported, but again it reduces the usefulness of the book as a 'beginner's book on L2 research'. However, the scope and quality of the collection demand that the volume should be present in the library of any institution which is involved in L2 learning, phonetics and speech communication.

William J. Barry, Jürgen Trouvain, Saarbrücken 